Check for updates

Cite this: RSC Adv., 2017, 7, 22054

\title{
Modification of a Pd-loaded electrode with a carbon nanotubes-polypyrrole interlayer and its dechlorination performance for 2,3-dichlorophenol $\uparrow$
}

\begin{abstract}
Zhirong Sun, (iD *a Ge Song, (DD ${ }^{\text {a }}$ Ran Du (iD) a and Xiang Hu (D) *b
A novel $\mathrm{Pd}$ loaded $\mathrm{Ti}$ electrode was prepared with a carbon nanotubes and polypyrrole interlayer modification, referred to as a Pd/CNTs-PPy/Ti electrode. Pretreated CNTs were deposited on the substrate uniformly by electrophoretic deposition technique. Modification by the CNTs-PPy interlayer made the Pd particles smaller and well-distributed. Pulsed-current electrodeposition technique led to more compact $\mathrm{Pd}$ particles. The hydrogen adsorption current value increased $55.3 \%$ and the electrochemical active surface area (EASA) increased $58.7 \%$ compared to the electrode without modification. The prepared Pd/CNTs-PPy/Ti electrode was employed in dechlorination of 2,3dichlorophenol (2,3-DCP) in aqueous solution. The potential impact factors on the electrocatalytic dechlorination were studied, including dechlorination current, initial $\mathrm{pH}$ value of catholyte, reaction temperature and common ions in aqueous solution. Complete dechlorination could be achieved within 70 min under the selected conditions i.e., current of $5 \mathrm{~mA}$, and an initial $\mathrm{pH}$ of 2.5 at ambient temperature. The common ions in aqueous solution, such as $\mathrm{NO}_{3}{ }^{-}, \mathrm{CO}_{3}{ }^{2-}, \mathrm{HCO}_{3}{ }^{-}, \mathrm{Mg}^{2+}, \mathrm{K}^{+}$and $\mathrm{Ca}^{2+}$, had no obvious effect on the electrocatalytic dechlorination within the scope of this investigation. The prepared $\mathrm{Pd} / \mathrm{CNTs}-\mathrm{PPy} / \mathrm{Ti}$ electrode exhibited promising dechlorination potential with higher

electrochemical activity.
\end{abstract}

Received 1st March 2017

Accepted 11th April 2017

DOI: $10.1039 / \mathrm{c} 7 \mathrm{ra0} 2515 \mathrm{~g}$

rsc.li/rsc-advances

\section{Introduction}

Chlorophenols (CPs), typical persistent organic pollutants (POPs), are widely used as raw materials in the production of wood preservatives and pesticides, ${ }^{1-3}$ and have been listed as priority pollutants by the United States Environmental Protection Agency (USEPA). ${ }^{4,5}$ They are highly toxic and resistant to biodegradation. They not only impact ecological security, but also threaten the life and health of human beings. Therefore, the degradation of CPs is of great significance.

There are several methods for CP removal, including biodegradation, ${ }^{6}$ chemical reduction, ${ }^{7,8}$ and electrocatalytic hydrogenolysis (ECH). ${ }^{9-11}$ ECH is considered an environmentally-friendly and highly-efficient technology in the dechlorination of CPs. Active hydrogen $\left(\mathrm{H}^{*}\right)$ is generated during the ECH process. $\mathrm{H}^{*}$ attacks CPs molecules chemisorbed on the electrode surface, leading to the dechlorination of CPs. ${ }^{12,13}$

${ }^{a}$ National Engineering Laboratory for Advanced Municipal Wastewater Treatment and Reuse Technology, Beijing University of Technology, Beijing 100124, P. R. China. E-mail: zrsun@bjut.edu.cn

${ }^{b}$ College of Chemical Engineering, Beijing University of Chemical Technology, Beijing 100029, P. R. China.E-mail: huxiang99@163.com

$\dagger$ Electronic supplementary information (ESI) available. See DOI: $10.1039 / \mathrm{c} 7 \mathrm{ra02515g}$
Palladium (Pd) is usually used as catalyst in ECH process due to its strong ability in adsorption ${ }^{14,15}$ and absorption of hydrogen to form hydride. ${ }^{16,17}$ Many researchers attempted to develop methods for improving the electrocatalytic performance of the electrode, such as changing the substrate of the catalytic electrode or modifying the electrode by special materials. Polypyrrole (PPy), a typical conductive polymer with high electrical conductivity and chemical stability, can be used as support material to obtain highly dispersed metallic particles. ${ }^{18,19}$ In our previous studies, ${ }^{20-23}$ PPy modified composite Pd electrodes shown higher electrochemical activity for CPs dechlorination, indicating the PPy was conducive to Pd particles deposition dispersedly, and it can also play co-catalysis role.

Carbon nanotubes (CNTs) have received increasing attention since they were discovered in $1991 .{ }^{24}$ CNTs exhibit good electric conductivity, large specific surface area and high energy density capacity, and have been regarded as an ideal catalyst support material. ${ }^{25,26}$ CNTs have been used as $\mathrm{Pd} / \mathrm{Fe}$ supporter for catalytic dechlorination of chlorinated organic compounds and complete removal of 2,4-dichlorophenol (2,4-DCP) could be achieved within 72 h. $^{27}$

CNTs-PPy composite material might provide synergistic effects for the ECH of CPs. However, to the best of our knowledge, no attention has been paid to the investigation of ECH 
cathode modified with both PPy and CNTs. In the present work, Ti mesh was selected as the substrate due to its good stability. CNTs were introduced as Pd catalyst support material, and we designed the composite electrode which was modified commonly with CNTs and PPy interlayer.

Pd particles were deposited by pulsed-current electrodeposition technique, instead of direct current electrodeposition technique, aiming to further improve the morphology of the electrode surface. The prepared composite electrode, palladium/carbon nanotubes-polypyrrole/titanium electrode (Pd/CNTs-PPy/Ti electrode) was expected to have a better performance and was applied to the dechlorination of 2,3dichlorophenol (2,3-DCP) in aqueous solution.

\section{Experimental}

\subsection{Chemicals and materials}

CNTs (>95\%, length of 10-30 $\mu \mathrm{m}$, outer diameter of $20-30 \mathrm{~nm}$ ) were obtained from Beijing Nachen Technology Co. Other chemicals and materials were similar to our previous research..$^{28,29}$

\subsection{Preparation of Pd/CNTs-PPy/Ti composite electrode}

2.2.1 Pretreatment of meshed Ti. Ti mesh size and its pretreatment method were same as those in our previous research.

2.2.2 Pretreatment of CNTs. Chemical oxidation of CNTs was conducted in a mixture of concentrated acids $\left(V_{\mathrm{HNO}_{3}}{ }^{-}\right.$ $\left.: V_{\mathrm{H}_{2} \mathrm{SO}_{4}}=1: 3\right)$ under the assistance of ultrasonication, followed by reflux at $333 \mathrm{~K}$ for further treatment. Different ultrasonication time and reflux time were discussed. The oxidized CNTs were washed to neutral with ultrapure water by centrifugation and filtration, and dried for later use.

2.2.3 Ti mesh surface modification with PPy film and CNTs. PPy was formed on the surface of pretreated meshed $\mathrm{Ti}$ mesh by electro-polymerization in a $50 \mathrm{~mL}$ mixed solution containing $0.04 \mathrm{mM}$ Py solution with assistance of 1.0 mM SLS, and the applied current was $3 \mathrm{~mA}$ and polymerization time was $5 \mathrm{~min}$. In the process of electro-polymerization, Ti mesh was set as anode, and Pt foil was used as cathode. Especially, the mixed solution was placed in ice bath.

CNTs-PPy/Ti supporting electrode was obtained by electrophoretic deposition of the pretreated CNTs with applied voltage of $10 \mathrm{~V}$ and time of $3 \mathrm{~min}$.

2.2.4 Deposition of Pd catalyst. Pd/CNTs-PPy/Ti electrode was prepared by pulsed-current electrodeposition, CNTs-PPy/ Ti was used as cathode and Pt foil was used as anode. Pulsed-current electrodeposition technique had better performance and Pd/CNTs-PPy/Ti electrode had higher hydrogen adsorption current value by comparison with current electrodeposition technique. Therefore, when it came to achieve the same hydrogen adsorption current value, pulsed-current electrodeposition technique could save more energy. The electrolyte solution consisted of $10 \mathrm{mM} \mathrm{PdCl}$ and $3.0 \mathrm{mM}$ SDBS. Pd particles were loaded on CNTs-PPy/Ti surface by 1000 cycles pulsed-current electrodeposition, with the pulse current density $\left(j_{\mathrm{p}}\right)$ of $12.5 \mathrm{~mA} \mathrm{~cm}^{-2}$ during the turn-on time, turn-on time $\left(T_{\text {on }}\right)$ of $1.25 \mathrm{~s}$ and turn-off time $\left(T_{\text {off }}\right)$ of $0.75 \mathrm{~s}$. For comparison, Pd/Ti electrode without modification of CNTs-PPy interlayer was also prepared under the same experimental conditions.

\subsection{Dechlorination experiments of 2,3-DCP}

The dechlorination processes were carried out in a twocompartment electrolytic cell (Fig. 1), similar with our previous research. ${ }^{30}$ 2,3-DCP initial concentration was $100 \mathrm{mg}$ $\mathrm{L}^{-1}$, and $0.05 \mathrm{M} \mathrm{Na}_{2} \mathrm{SO}_{4}$ solution was used as supporting electrolyte in both catholyte and anolyte. Potential impact factors, including different applied current, different initial $\mathrm{pH}$ values of catholyte adjusted with $0.05 \mathrm{M} \mathrm{H}_{2} \mathrm{SO}_{4}$ solution and common ions in aqueous solution, were discussed.

\subsection{Analytical methods}

The analytical equipments and methods for cyclic voltammetry (CV), transmission microscope (TEM), scanning electron microscope (SEM), X-ray diffractometer (XRD), inductively coupled plasma-atomic emission spectrometry (ICP-AES), and ion chromatography (IC) followed our previous relevant research. ${ }^{31,32}$ The level of CNTs surface charge was characterized by the zeta potential (Microtrac Zetatrac, USA), the concentration of CNTs dispersion was $0.5 \mathrm{mg} \mathrm{mL}^{-1}$, which $\mathrm{pH}$ value was adjusted by $\mathrm{H}_{2} \mathrm{SO}_{4}$ solution and $\mathrm{NaOH}$ solution. The concentrations of 2,3-DCP and intermediate products were detected by high performance liquid chromatography (HPLC, waters 1525 binary pump and waters $2489 \mathrm{UV} /$ visible detector, USA, C18 column, Kromasil) at wavelength of $280 \mathrm{~nm}$. The mobile phase was $30 \%$ water and $70 \%$ methanol with flow rate of $0.8 \mathrm{~mL} \min ^{-1}$.

\subsection{Calculation methods}

The 2,3-DCP removal efficiency and the dechlorination efficiency were calculated following the methods reported in the literature. ${ }^{30}$

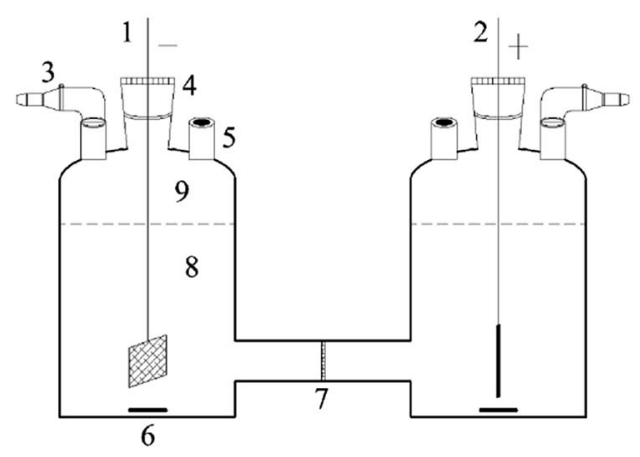

Fig. 1 A schematic of the electrolytic cell for batch experiments, (1) $\mathrm{Pd} / \mathrm{CNTS}-\mathrm{PPy} / \mathrm{Ti}$ cathode; (2) Pt anode; (3) expandable syringe; (4) gas-tight adapter; (5) sampling port; (6) stir bar; (7) cation-exchange membrane; (8) electrolyte $(30 \mathrm{~mL}) ;(9)$ headspace of cell $(10 \mathrm{~mL})$. All adapters were fixed with tape and clamps. 


\section{Results and discussion}

\subsection{Preparation parameters of CNTs pretreatment and electrophoretic deposition}

To obtain a stable and high-efficient electrode, fabrication of homogeneous CNTs film on the PPy/Ti supporting electrode was an essential step, and it was achieved by electrophoretic deposition method. Several factors affect the electrophoretic deposition process, especially the zeta potential of CNTs suspension and the electrophoretic deposition time. ${ }^{33,34}$

3.1.1 Parameters of CNTs pretreatment. Considering raw CNTs were inert and hydrophobic. It is vital to disperse CNTs homogeneously in a suitable solvent before electrophoretic deposition process. ${ }^{35}$ Carboxyl groups could be introduced on the surface of CNTs by chemical oxidation treatment and provided negative surface charge, ${ }^{36-38}$ so the oxidized CNTs had good hydrophilicity and could disperse in water uniformly, and this which was beneficial to the electrophoretic deposition process.

Fig. 2 shows the TEM images of CNTs under different ultrasonication time and reflux time. As shown in Fig. 2a, the raw CNTs had impurities and were poor dispersibility, which indicated the process of CNTs oxidation treatment was insufficient by ultrasonication for $1 \mathrm{~h}$ and reflux for $1 \mathrm{~h}$ (Fig. $2 \mathrm{~b}$ ). When extending ultrasonication time to $4 \mathrm{~h}$, the treated CNTs behaved better dispersibility. Similar morphologies could be seen from Fig. $2 \mathrm{c}$ and $\mathrm{d}$ when the reflux time was further extended to $2 \mathrm{~h}$. The oxidized CNTs appeared clean and ordered, and it indicated that the impurities were almost removed.

A higher absolute value of the zeta potential indicates stability of CNTs' suspensions, which is favorable to CNTs

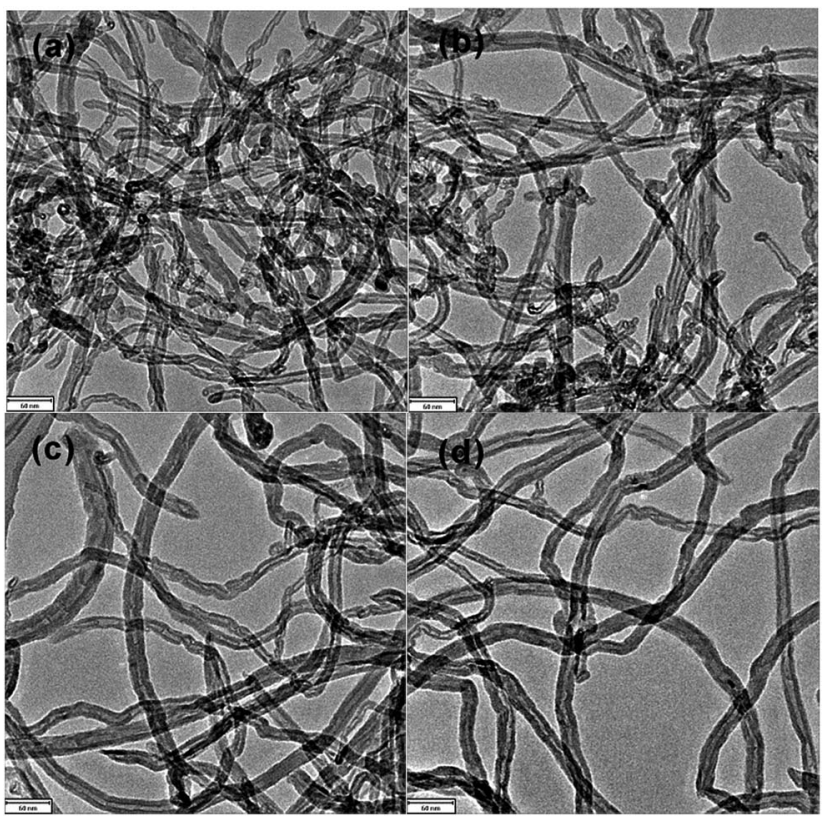

Fig. 2 TEM images of CNTs with different chemical oxidation conditions. Raw CNTs (a), ultrasonication for $1 \mathrm{~h}$ and reflux for $1 \mathrm{~h}$ (b) ultrasonication for $4 \mathrm{~h}$ and reflux for $1 \mathrm{~h}$ (c), ultrasonication for $4 \mathrm{~h}$ and reflux for $2 \mathrm{~h}(\mathrm{~d})$. deposition. If the absolute value of zeta potential is lower than $25 \mathrm{mV}$, the repulsive force between the particles is not strong enough to overcome the van der Waals force, ${ }^{34,39}$ resulting in agglomeration and sedimentation of the particles.

Fig. 3 shows the zeta potentials of CNTs' suspension with the different $\mathrm{pH}$ values, $\mathrm{H}_{2} \mathrm{SO}_{4}$ solution and $\mathrm{NaOH}$ solution were used to adjust the $\mathrm{pH}$ value of CNTs' suspension. The highest zeta potential absolute value, $53 \mathrm{mV}$, was achieved at $\mathrm{pH}$ value of 6 under condition of ultrasonication for $4 \mathrm{~h}$ and reflux for $2 \mathrm{~h}$. The zeta potential absolute value became higher with the extension of reaction time, which indicated better stability of CNTs' suspension. This was because more active groups were introduced on the surface of CNTs with longer reaction time.

Therefore, ultrasonication for $4 \mathrm{~h}$ and reflux for $2 \mathrm{~h}$ at CNTs suspension pH value of 6 were selected as the appropriate CNTs pretreatment conditions.

3.1.2 Parameters of CNTs electrophoretic deposition. Electrophoretic deposition time of CNTs was investigated. When deposition time was only $1 \mathrm{~min}$, a small amount of CNTs were loaded on the surface of electrode (Fig. 4a). When deposition time was extended to 3 min, a compact and uniform CNTs film was achieved (Fig. 4b). But when the deposition time continued to increase, we could clearly see the deposition layer of CNTs partly fall off as it was extensively thick. Consequently, 3 min was employed as the deposition time.

\subsection{Characterization of Pd/CNTs-PPy/Ti electrode}

3.2.1 Morphologies of electrode surface. Fig. 5 shows the SEM images of the prepared electrodes. Pd particles on the surface of $\mathrm{Pd} / \mathrm{Ti}$ electrode presented spherical agglomerates (Fig. 5a). Pd particles on the surface of Pd/CNTs-PPy/Ti electrode (Fig. 5b) were well-distributed with the modification of CNTs-PPy interlayer. It can be inferred that CNTs-PPy interlayer was favorable to the uniform dispersion of Pd particles, which would benefits the stability of the electrode.

In previous studies, ${ }^{23} \mathrm{Pd}$ particles deposited on the surface of Pd/PPy-SDBS/Ti electrode with conch-like shape, interestingly, the surface morphology of the Pd/CNTs-PPy/Ti electrode in this study appeared "pinpoint" shape, more compact and uniform, which could provide higher specific surface area and larger reaction contact sites for dechlorination process. This may be

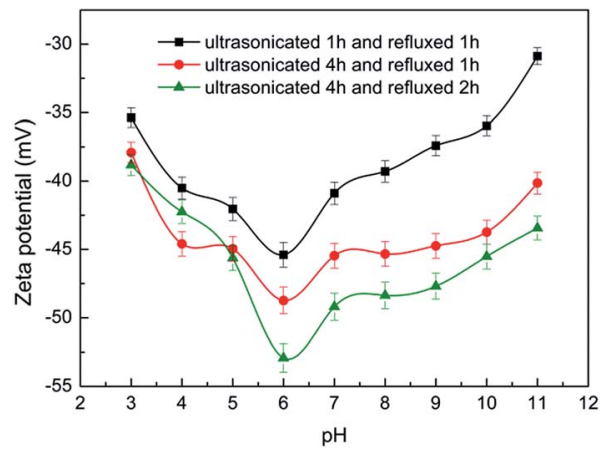

Fig. 3 Zeta potentials of CNTs suspension as a function of $\mathrm{pH}$ and pretreatment condition. 


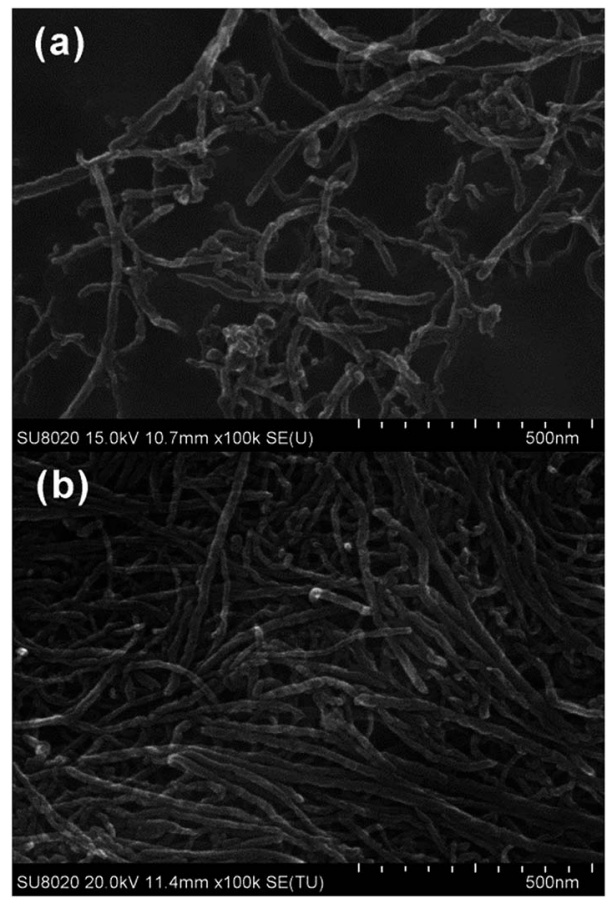

Fig. 4 SEM images of CNTs films under different electrophoretic deposition time. 1 min (a), 3 min (b).

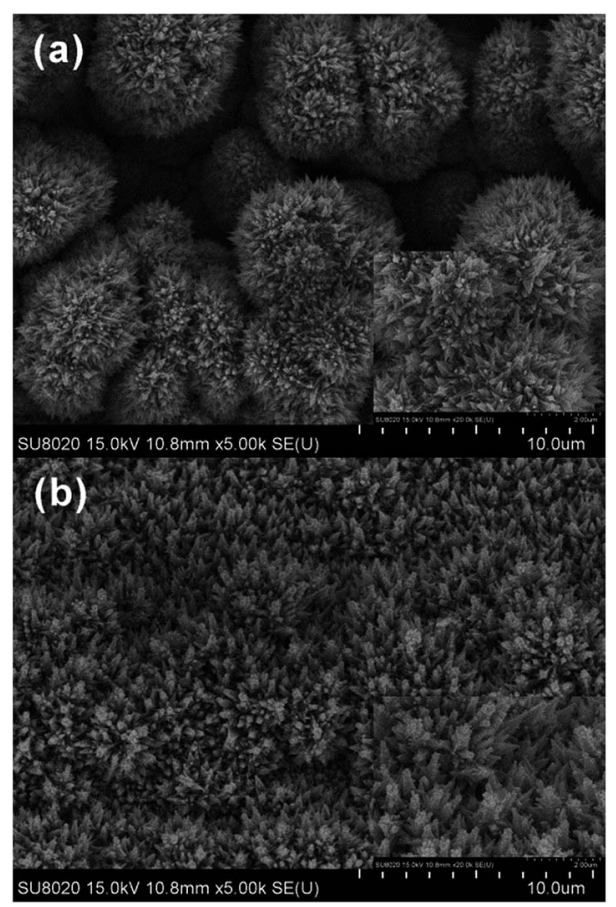

Fig. 5 SEM images $(5000 \times$ ) of Pd/Ti electrode (a) and Pd/CNTs-PPy/ Ti electrode (b). The insets are the SEM images $(20000 \times)$.

due to the effect of pulsed-current electrodeposition. As reported in the literature, ${ }^{40}$ dechlorination of CPs at Pd loaded electrode conformed to hydrogen spillover mechanism. $\mathrm{H}^{*}$ generated firstly on a polarized Pd particle and then diffused to a less polarized nearby Pd article by spillover. It was proposed that the pinpoint like Pd on the Pd/CNTs-PPy/Ti could be polarized easily, which was conducive to $\mathrm{H}^{*}$ generation and ECH of CPs.

3.2.2 Crystallite features. Fig. 6 shows the XRD patterns of $\mathrm{Pd} / \mathrm{CNTs}-\mathrm{PPy} / \mathrm{Ti}$ electrode and Pd/Ti electrode. The five strong diffraction peaks at $2 \theta$ of $40.2,46.7,68.2,82.1$ and 86.7 were attributed to Pd (111), Pd (200), Pd (220), Pd (311) and Pd (222) crystal lattice, respectively, representing the face-centered cubic (FCC) crystal structure. The crystallite size of Pd on Pd/CNTs$\mathrm{PPy} /$ Ti electrode was $15.8 \mathrm{~nm}$, which was smaller than that on Pd/ Ti electrode $(19.9 \mathrm{~nm})$, which were calculated by XRD bundled software (EVA). The smaller crystallite size of the Pd/CNTs-PPy/Ti electrode might be due to the effect of CNTs-PPy interlayer.

3.2.3 CV test. Fig. 7 shows the $\mathrm{CV}$ curves of $\mathrm{Pd} / \mathrm{CNTs}-\mathrm{PPy} / \mathrm{Ti}$ electrode and $\mathrm{Pd} / \mathrm{Ti}$ electrode in $0.5 \mathrm{M} \mathrm{H}_{2} \mathrm{SO}_{4}$ solution. In the potential range from -0.7 to $0.7 \mathrm{~V} v$ s. $\mathrm{Hg} / \mathrm{Hg}_{2} \mathrm{SO}_{4}$, two pairs of reduction and oxidation peaks were observed, the oxidation peaks existed from $100 \mathrm{mV}$ to $600 \mathrm{mV}$ and $-500 \mathrm{mV}$ to $-300 \mathrm{mV}$ corresponded to the oxidation of Pd and the desorption of hydrogen, respectively. It can be seen the curve existed from $-300 \mathrm{mV}$ to $200 \mathrm{mV}$ related to the reduction of Pd oxide. A sort of plateau around $-600 \mathrm{mV}$ that could indeed be adsorption of hydrogen, and then massive hydrogen discharge around $-800 \mathrm{mV} .^{41}$ It can be apparently observed that Pd/CNTs-PPy/Ti electrode displayed a higher hydrogen adsorption peak current than Pd/Ti electrode, which suggested the Pd/CNTs-PPy/Ti electrode possessed faster reaction rate under the same conditions. ${ }^{42}$ The CNTs-PPy/Ti electrode had a better chargedischarge capacity compared with $\mathrm{PPy} / \mathrm{Ti}$ electrode and $\mathrm{Ti}$ electrode (shown in Fig. S1†). The CNTs-PPy interlayer may act as co-catalyst to ECH. Pd/CNTs-PPy/Ti electrode may offer more chances for the ECH and exhibit higher electrocatalytic activity in the dechlorination reaction.

As shown in Table 1, the hydrogen adsorption current value (at about $-600 \mathrm{mV}$ ) of Pd/CNTs-PPy/Ti electrode was improved to $-160 \mathrm{~mA}$, which increased $55.3 \%$ compared with that of $\mathrm{Pd} /$ Ti electrode, $-103 \mathrm{~mA}$. According to the mechanism of $\mathrm{ECH},{ }^{43,44}$ the higher hydrogen adsorption current value in the voltammogram, the more hydrogen atoms were adsorbed on the electrode, which would contribute to a higher efficiency for electrochemical reductive dechlorination of CPs. Therefore, the electrocatalytic performance of electrodes was improved with the modification of CNTs-PPy interlayer. Pd/CNTs-PPy/Ti electrode had better potential for CPs dechlorination.

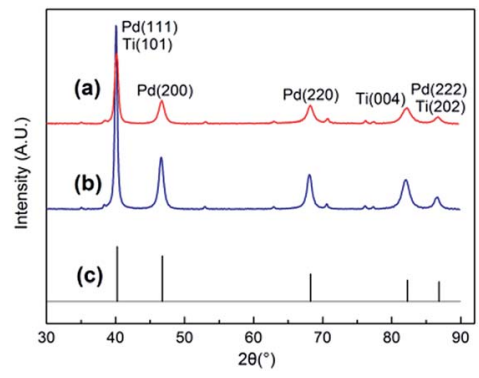

Fig. 6 XRD patterns of Pd/CNTs-PPy/Ti electrode (a), Pd/Ti electrode (b) and Pd (JCPDS-ICDD, 87-0638). 


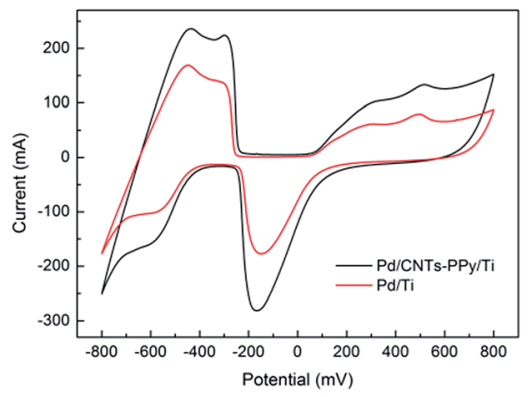

Fig. $7 \mathrm{CV}$ curves of prepared electrodes in $0.5 \mathrm{M} \mathrm{H}_{2} \mathrm{SO}_{4}$ solution. Scan rate: $50 \mathrm{mV} \mathrm{s}^{-1}$.

Table 1 Characterization parameters of prepared electrodes. $j_{\mathrm{p}}=12.5$ $\mathrm{mA} \mathrm{cm}{ }^{-2}, T_{\text {on }}=1.25 \mathrm{~s}, T_{\text {off }}=0.75 \mathrm{~s}, 1000$ cycles, $C_{\text {Pd(II) }}=10 \mathrm{mmol} \mathrm{L}^{-1}$, $C_{\text {SDBS }}=3.0 \mathrm{mmol} \mathrm{L}^{-1}$

\begin{tabular}{llll}
\hline Electrode & $\begin{array}{l}\text { Hydrogen adsorption } \\
\text { current }(\mathrm{mA})\end{array}$ & $\begin{array}{l}\text { Pd } \\
\left.(\mathrm{mg} \mathrm{cm})^{-2}\right)\end{array}$ & $\begin{array}{l}\text { EASA } \\
\left(\mathrm{m}^{2} \mathrm{~g}^{-1}\right)\end{array}$ \\
\hline $\mathrm{Pd} / \mathrm{CNTs}-\mathrm{PPy} / \mathrm{Ti}$ & 160 & 3.55 & 16.35 \\
$\mathrm{Pd} / \mathrm{Ti}$ & 103 & 3.55 & 10.30
\end{tabular}

The loading levels of Pd particles on the prepared electrodes were investigated by ICP-AES. The Pd content on Pd/CNTs-PPy/ Ti electrode and $\mathrm{Pd} / \mathrm{Ti}$ electrode were both $3.55 \mathrm{mg} \mathrm{cm}^{-2}$.

The electrochemical active surface areas (EASA) of the prepared electrodes were calculated in light of the literatures. ${ }^{45-47}$ EASA $\approx Q / K m$, where charge $Q$ is based on the charge of hydrogen atoms adsorption/desorption in the CV test, $m$ is the mass of Pd of the prepared electrodes and $K$ is the Pd conversion factor which is $210 \mu \mathrm{C} \mathrm{cm}^{-2}$. The calculated EASA values were shown in Table 1, the EASA of Pd/CNTs-PPy/Ti electrode was improved to $16.35 \mathrm{~m}^{2} \mathrm{~g}^{-1}$, which increased $58.7 \%$ compared with that of the Pd/Ti electrode, $10.30 \mathrm{~m}^{2} \mathrm{~g}^{-1}$. Pd/CNTs-PPy/Ti electrode with lager EASA was more beneficial to the electrocatalytic reductive dechlorination of chlorophenols. The utilization efficiency of Pd was improved with the modification of CNTs-PPy interlayer.

\subsection{Parameters of 2,3-DCP dechlorination}

3.3.1 Effects of dechlorination currents. The influence of dechlorination current was investigated with initial catholyte $\mathrm{pH}$ of 2.0 under different constant currents $(3 \mathrm{~mA}, 5 \mathrm{~mA}, 8 \mathrm{~mA}$ and $10 \mathrm{~mA}$, respectively). Fig. 8a plots the effect of constant current on the removal of 2,3-DCP. The removal was accelerated with the increase of current, reached $47 \%$ and $100 \%$ at $70 \mathrm{~min}$ with the applied current of $3 \mathrm{~mA}$ and $5 \mathrm{~mA}$, respectively. When the current was increased to $8 \mathrm{~mA}$ and $10 \mathrm{~mA}$, complete removal of 2,3-DCP could be achieved within $50 \mathrm{~min}$.

Fig. $8 \mathrm{~b}$ plots the dechlorination efficiencies of 2,3-DCP varying with the applied current. During the first $30 \mathrm{~min}$, higher dechlorination current led to higher dechlorination efficiency, which consisted with the removal tendency of 2,3-DCP. Dechlorination efficiency decreased when current increased after $30 \mathrm{~min}$. 2,3-DCP dechlorination efficiencies at $70 \mathrm{~min}$ were
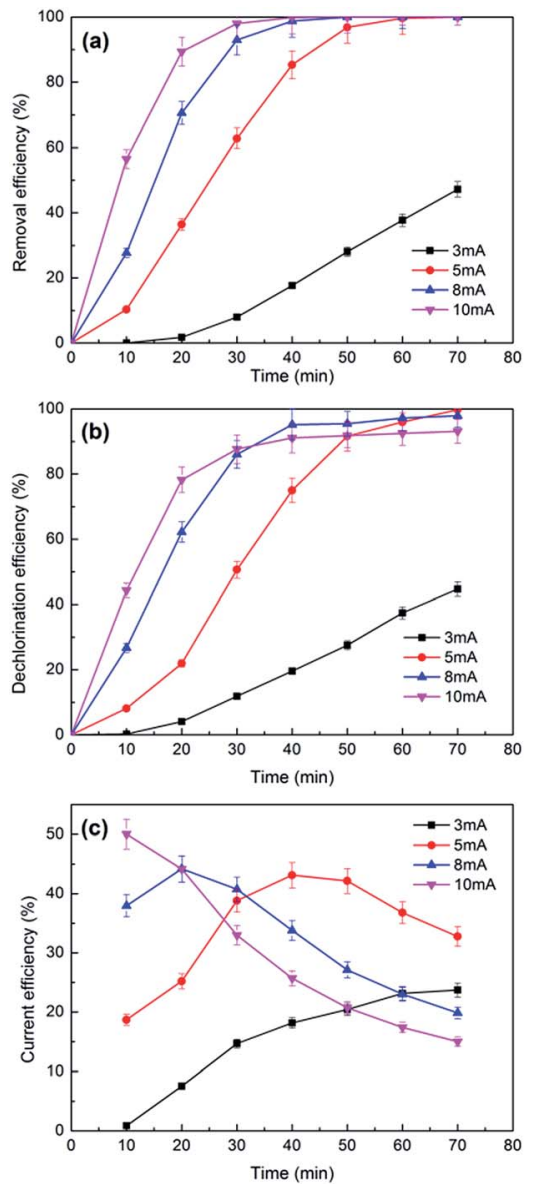

Fig. 8 The effects of currents on the removal (a), dechlorination efficiency (b) and current efficiency (c) of 2,3-DCP dechlorination. Initial $\mathrm{pH}, 2.0$.

$100 \%, 98 \%$ and $93 \%$ with the current of $5 \mathrm{~mA}, 8 \mathrm{~mA}$ and $10 \mathrm{~mA}$, respectively. Dechlorination efficiency was lower than removal, possibly because the adsorption and dechlorination were carried out simultaneously, part of the adsorbed 2,3-DCP were not dechlorinated in time.

According to the previous studies, ${ }^{\mathbf{4 8 , 4 9}}$ hydrogen evolution reaction (HER) occurred during the ECH process. The side reaction HER would be speeded up with the current increasing. In addition, when the concentration of 2,3-DCP decreased gradually, the HER process became more strong, which inhibited the ECH process. Fig. 8c shows the current efficiencies of 2,3-DCP dechlorination under different currents. When current of $10 \mathrm{~mA}$ was employed, the current efficiency decreased as time went on, indicated that HER influenced dechlorination process seriously at $10 \mathrm{~mA}$. When current of $3 \mathrm{~mA}$ was used, the current efficiency increased over time. When currents of $5 \mathrm{~mA}$ and $8 \mathrm{~mA}$ were used, current efficiencies increased at the early stage and decreased latterly. The current efficiencies at $70 \mathrm{~min}$ under $8 \mathrm{~mA}$ and $10 \mathrm{~mA}$ were $19 \%$ and 15\%, respectively, much lower than $32 \%$ achieved under $5 \mathrm{~mA}$. Considering the reaction efficiency and the cost, $5 \mathrm{~mA}$ was selected as the appropriate dechlorination current. The lower energy consumption was part of cleaner production. 
3.3.2 Effects of initial pH values of catholyte. Under the constant current of $5 \mathrm{~mA}$, the effect of initial $\mathrm{pH}$ of catholyte was investigated with different $\mathrm{pH}$ values of 2.0, 2.5, 2.8 and 3.2. Fig. 9 shows the influence of initial $\mathrm{pH}$ of catholyte on the 2,3DCP dechlorination. 2,3-DCP could not be completely removed and dechlorinated within $70 \mathrm{~min}$ with initial $\mathrm{pH}$ value of 3.2, which might be due to the insufficient $\mathrm{H}^{*}$. When initial $\mathrm{pH}$ value was 2.8, 100\% removal and 95\% dechlorination efficiency were obtained at $70 \mathrm{~min}$. Complete removal and 100\% dechlorination efficiency could be achieved at $\mathrm{pH}$ value of 2.5 and 2.0 at $70 \mathrm{~min}$. More hydrogen ions accelerated the generation of $\mathrm{H}^{*}$, which promoted the ECH process as well as HER process. The current efficiency under $\mathrm{pH} 2.0$ was lower than that under $\mathrm{pH}$ 2.5 due to the stronger HER reaction. Table 2 lists the variation of $\mathrm{pH}$ values before and after the dechlorination. Initial $\mathrm{pH}$ value of 2.5 was suitable in consideration that neutral solution was beneficial to the subsequent treatment.

3.3.3 Effects of temperature. Under constant current of 5 $\mathrm{mA}$ and catholyte initial $\mathrm{pH}$ of 2.5 , the dechlorination experiments were conducted with the temperature of $298 \mathrm{~K}, 308 \mathrm{~K}, 318$ $\mathrm{K}$ and $328 \mathrm{~K}$, respectively. As shown in Fig. 10, the removal and dechlorination efficiency were improved with temperature increased. At $298 \mathrm{~K}$ and $308 \mathrm{~K}, 100 \%$ removal and $100 \%$
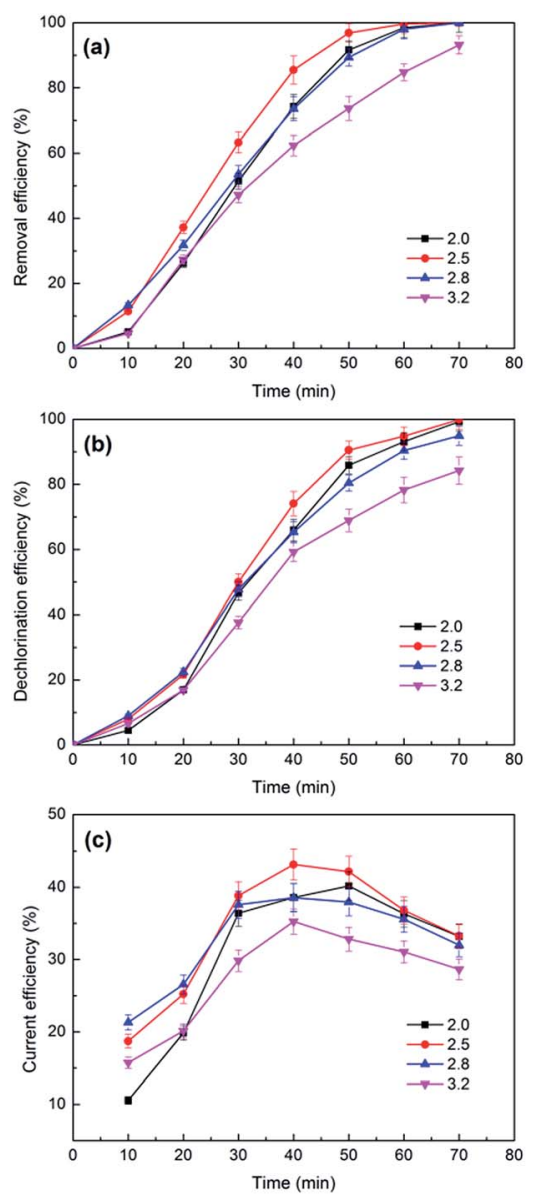

Fig. 9 The effects of catholyte initial $\mathrm{pH}$ values on the removal (a) and dechlorination efficiency (b) and current efficiency (c) of 2,3-DCP dechlorination. Constant current, $5 \mathrm{~mA}$.
Table 2 Variation of $\mathrm{pH}$ values of catholyte before and after dechlorination process. $I=5 \mathrm{~mA}, t=70 \mathrm{~min}, C_{0,2,3-\mathrm{DCP}}=100 \mathrm{mg} \mathrm{L}^{-1}, C_{\mathrm{Na}_{2} \mathrm{SO}_{4}}$ $=0.05 \mathrm{~mol} \mathrm{~L}^{-1}$

\begin{tabular}{llllr}
\hline \multicolumn{5}{c}{$\mathrm{pH}$ value } \\
\hline Initial & 2.00 & 2.50 & 2.80 & 3.20 \\
Terminal & 2.38 & 6.08 & 9.35 & 11.19
\end{tabular}

dechlorination efficiency of 2,3-DCP dechlorination were achieved at $70 \mathrm{~min}$. Removal efficiency reached $100 \%$ at $60 \mathrm{~min}$ and dechlorination efficiency reached $100 \%$ at $70 \mathrm{~min}$ with the temperature of $318 \mathrm{~K}$. When temperature was increased to 328 $\mathrm{K}, 2,3$-DCP could be completely removed at $50 \mathrm{~min}$ and thoroughly dechlorinated at $60 \mathrm{~min}$. The high reaction rate was observed at high temperature.

3.3.4 Effects of common ions in aqueous solution. The effects of common anions $\left(\mathrm{NO}_{3}{ }^{-}, \mathrm{CO}_{3}{ }^{2-}\right.$ and $\left.\mathrm{HCO}_{3}{ }^{-}\right)$and cations $\left(\mathrm{Mg}^{2+}, \mathrm{K}^{+}\right.$and $\left.\mathrm{Ca}^{2+}\right)$ in aqueous solution were investigated. The same concentration level of $100 \mathrm{mg} \mathrm{L}^{-1}$ was selected for the discussed common ions. Experiments without the ions mentioned above were conducted for comparison.

The dechlorination experiments with addition of $\mathrm{NO}_{3}{ }^{-}$, $\mathrm{CO}_{3}{ }^{2-}$ and $\mathrm{HCO}_{3}{ }^{-}$were investigated under constant current of 5 $\mathrm{mA}$ and catholyte initial $\mathrm{pH}$ of 2.5. Results showed that the removal and dechlorination efficiency of 2,3-DCP could reach $100 \%$ within $70 \mathrm{~min}$, almost similar to the control experiment, as shown in Fig. S2. $\dagger$ The addition of $\mathrm{NO}_{3}{ }^{-}, \mathrm{CO}_{3}{ }^{2-}$ and $\mathrm{HCO}_{3}{ }^{-}$ had no obvious effect on the dechlorination.

Similarly, dechlorination experiments with addition of $\mathrm{Mg}^{2+}$, $\mathrm{K}^{+}, \mathrm{Ca}^{2+}$ were investigated under constant current of $5 \mathrm{~mA}$ and catholyte initial $\mathrm{pH}$ of 2.5 . Both the removal and dechlorination efficiency of 2,3-DCP could reach 100\%, as shown in Fig. S3. $\dagger$ No
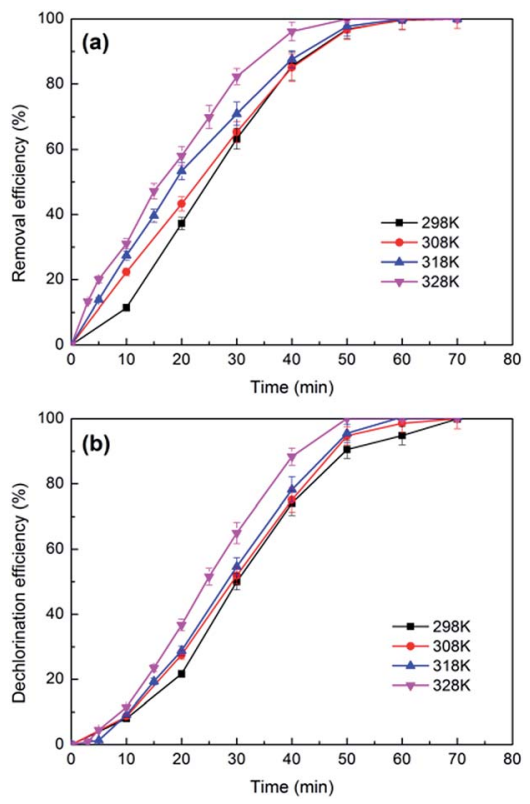

Fig. 10 The effects of temperature on the removal (a) and dechlorination efficiency (b) of 2,3-DCP dechlorination. Constant current, 5 $\mathrm{mA}$; initial $\mathrm{pH}, 2.5$. 
distinct change was observed in comparison to the control experiment, indicating that $\mathrm{Mg}^{2+}, \mathrm{K}^{+}, \mathrm{Ca}^{2+}$ had no obvious effect on the dechlorination.

\subsection{Dechlorination pathways of 2,3-DCP}

Fig. 11 plots the concentrations of 2,3-DCP and intermediates during the dechlorination. As the dechlorination of 2,3-DCP progressing, the concentration of phenol increased gradually. The concentration of 2-chlorophenol (2-CP) increased in the first $30 \mathrm{~min}$ and then decreased. No 3-chlorophenol (3-CP) was detected during the whole dechlorination process. Therefore, it was inferred that the pathways of 2,3-DCP dechlorination might follow two routes (Fig. 12): meta-Cl was dechlorinated firstly, generating 2-CP, which was dechlorinated further to phenol (route a); meta-Cl and ortho-Cl were dechlorinated simultaneously (route b). Phenol was the main dechlorination product of 2,3-DCP. The meta-Cl was substituted easier due to the steric hindrance effect. ${ }^{50,51}$

\subsection{Long term performance of Pd/CNTs-PPy/Ti electrode}

Under constant current of $5 \mathrm{~mA}$ and catholyte initial $\mathrm{pH}$ of 2.5, eight times consecutive reduction experiments with 2,3-DCP initial concentration of $100 \mathrm{mg} \mathrm{L}^{-1}$ were conducted. As shown in Fig. 13, complete removal and dechlorination could be achieved within $70 \mathrm{~min}$ in each experiment. This indicated that $\mathrm{Pd} /$ CNTs-PPy/Ti electrode had good stability.

\subsection{The electrocatalytic comparison of Pd/CNTs-PPy/Ti electrode, Pd/PPy/Ti electrode, Pd/CNTs/Ti electrode and Pd/ Ti electrode}

The contrast experiments were used to further reveal the synergistic effect of Pd, CNTs, and polypyrrole for dechlorination of 2,3-dechlorophenol. In Fig. 14, it could be seen that the CV curve of Ti electrode nearly is a straight line, which meant the capacity of adsorbing hydrogen of $\mathrm{Ti}$ electrode could be negligible comparing with PPy/Ti electrode. Besides, compared with Ti electrode, it could be clearly seen that the increased hydrogen adsorption current of CNTs-PPy/Ti electrode (16.0 $\mathrm{mA})$ was higher than the sum $(6.1 \mathrm{~mA})$ of PPy/Ti electrode and CNTs/Ti electrode. So the better electrocatalytic performance of

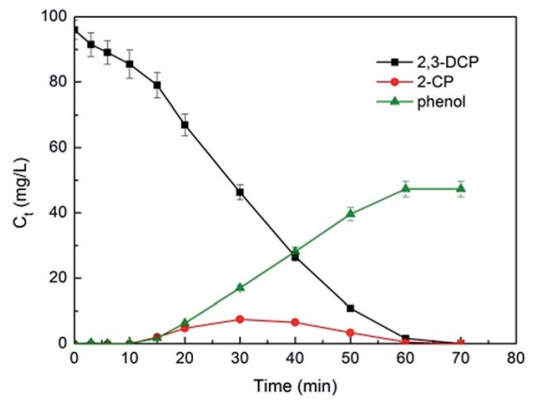

Fig. 11 Variations of 2,3-DCP concentration and intermediate products concentration during the dechlorination. Constant current, $5 \mathrm{~mA}$; initial $\mathrm{pH}, 2.5$.

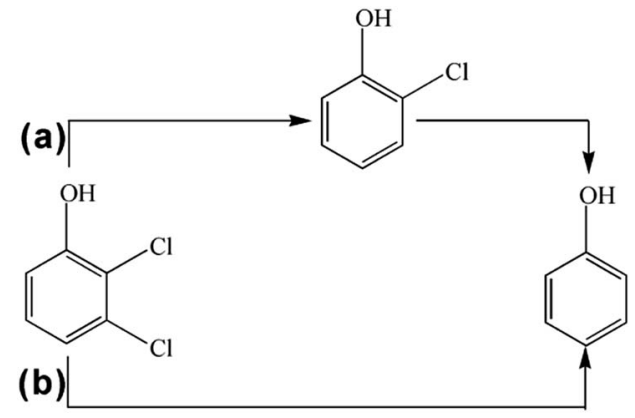

Fig. 12 Proposed pathways of 2,3-DCP dechlorination.
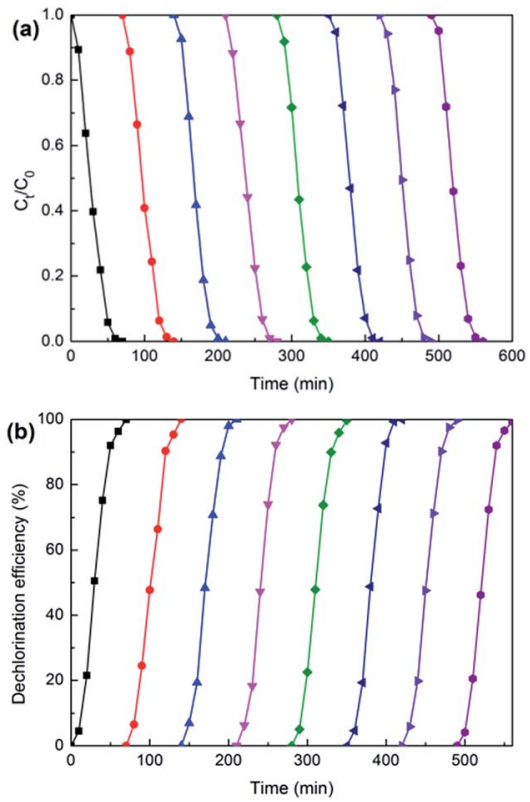

Fig. 13 Variations of 2.3-DCP concentration (a) and dechlorination efficiency (b) during the repeated dechlorinations of 2,3-DCP on Pd/ CNTs-PPy/Ti electrode. Constant current, 5 mA; initial pH, 2.5.

CNTs-PPy/Ti electrode was likely to be the synergistic effect of Pd, CNTs, and polypyrrole.

In Fig. 15, it could be found that hydrogen adsorption current of CNTs-PPy/Ti electrode can be negligible comparing with $\mathrm{Pd} / \mathrm{CNTs}-\mathrm{PPy} / \mathrm{Ti}$ electrode and $\mathrm{Pd} / \mathrm{Ti}$ electrode. And

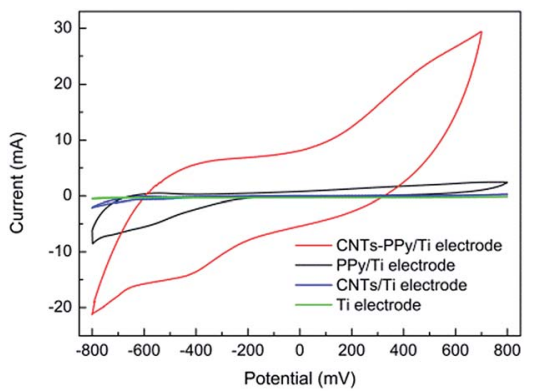

Fig. $14 \mathrm{CV}$ curves of CNTs-PPy/Ti electrode, PPy/Ti electrode, CNTs/Ti electrode and Ti electrode in $0.5 \mathrm{M} \mathrm{H}_{2} \mathrm{SO}_{4}$ solution. Scan rate: $50 \mathrm{mV} \mathrm{s}^{-1}$. 


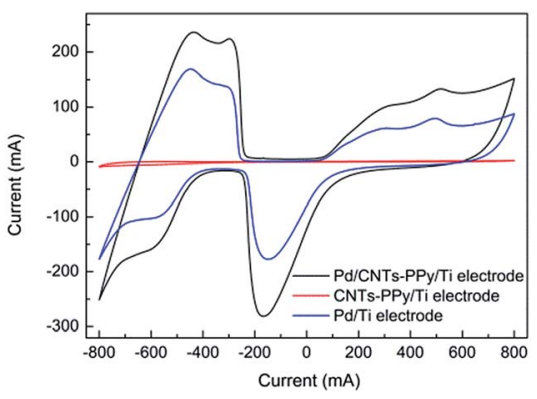

Fig. 15 CV curves of Pd/CNTs-PPy/Ti electrode, CNTs-PPy/Ti electrode and $\mathrm{Pd} / \mathrm{Ti}$ electrode in $0.5 \mathrm{M} \mathrm{H}_{2} \mathrm{SO}_{4}$ solution. Scan rate: $50 \mathrm{mV} \mathrm{s}^{-1}$.

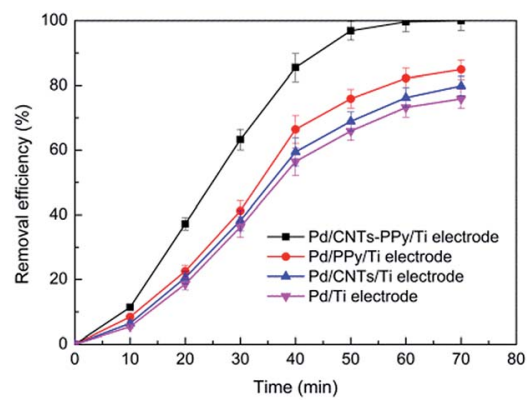

Fig. 16 The removal efficiency of Pd/CNTs-PPy/Ti electrode, Pd/PPy/ $\mathrm{Ti}$ electrode, $\mathrm{Pd} / \mathrm{CNTS} / \mathrm{Ti}$ electrode and $\mathrm{Pd} / \mathrm{Ti}$ electrode on 2,3-DCP dechlorination. Constant current, $5 \mathrm{~mA}$; initial pH, 2.5 .

hydrogen adsorption current of Pd/CNTs-PPy/Ti electrode was higher than the $\mathrm{Pd} / \mathrm{Ti}$ electrode. It was likely to be the synergistic effect of Pd, CNTs, and polypyrrole to improve the electrocatalytic performance of the electrode. Besides, we further investigated the removal efficiency of $\mathrm{Pd} / \mathrm{CNTS}-\mathrm{PPy} / \mathrm{Ti}$ electrode, $\mathrm{Pd} / \mathrm{PPy} / \mathrm{Ti}$ electrode, $\mathrm{Pd} / \mathrm{CNTs} / \mathrm{Ti}$ electrode and $\mathrm{Pd} / \mathrm{Ti}$ electrode on 2,3-DCP dechlorination under the same conditions (constant current, $5 \mathrm{~mA}$; initial pH, 2.5). Fig. 16 showed the removal efficiency of Pd/CNTs-PPy/Ti electrode was higher than the other three electrode, and the increased removal efficiency of the Pd/CNTs-PPy/Ti electrode $(24.1 \%)$ was higher than the sum $(13.0 \%)$ of $\mathrm{Pd} / \mathrm{PPy} / \mathrm{Ti}$ electrode and Pd/CNTs/Ti electrode compared with $\mathrm{Pd} / \mathrm{Ti}$ electrode at $70 \mathrm{~min}$, which meant the electrocatalytic performance of the electrode was promoted distinctively when the modified interlayer was CNTs-PPy. So the better electrocatalytic performance of Pd/CNTs-PPy/Ti electrode was likely to be the synergistic effect of Pd, CNTs, and polypyrrole.

\section{Conclusions}

Pd loaded electrode with the modification of CNTs-PPy interlayer showed higher electrocatalytic activity. CNTs-PPy interlayer made Pd particles uniformly deposit on the electrode surface. Pulsed-current electrodeposition technique made the electrode surface get a finer grain structure, and Pd particles were more compact and smaller. Pd/CNTs-PPy/Ti electrode had higher hydrogen adsorption current value of $-160 \mathrm{~mA}$ and larger EASA of $16.35 \mathrm{~m}^{2} \mathrm{~g}^{-1} \cdot 2,3$-DCP could be completely removed and $100 \%$ dechlorinated under constant current of 5 $\mathrm{mA}$ and catholyte initial pH of 2.5 within $70 \mathrm{~min}$ on Pd/CNTs$\mathrm{PPy} / \mathrm{Ti}$ electrode. The common ions in aqueous solution including $\mathrm{NO}_{3}{ }^{-}, \mathrm{CO}_{3}{ }^{2-}, \mathrm{HCO}_{3}{ }^{-}, \mathrm{Mg}^{2+}, \mathrm{K}^{+}$and $\mathrm{Ca}^{2+}$, had no obvious effect on the dechlorination within the scope of investigation. The intermediates of 2,3-DCP dechlorination were 2$\mathrm{CP}$ and phenol. Pd/CNTs-PPy/Ti electrode presents the application potential due to its good stability and high electrocatalytic activity.

\section{Acknowledgements}

This work was supported by National Natural Science Foundation of China (51478014 and 51278006), Cultivation Fund for Beijing New Century Hundred, Thousand and Ten Thousand Talents Project.

\section{Notes and references}

1 D. M. Zhao, Y. Y. Zheng, M. Li, S. A. Baig, D. L. Wu and X. H. Xu, Ultrason. Sonochem., 2014, 21, 1714-1721.

2 F. Y. Kong, A. J. Wang and H. Y. Ren, Bioresour. Technol., 2014, 166, 252-258.

3 X. Y. Wang, M. P. Zhu, H. L. Liu, J. Ma and F. Li, Sci. Total Environ., 2013, 449, 157-167.

4 X. Fan, K. Lai, L. Wang, H. Qiu, J. Yin, P. Zhao, S. Pan, J. Xu and C. Wang, J. Mater. Chem. A, 2015, 3, 12179-12187.

5 K. Wang, P. Chen and S. Huang, Anal. Bioanal. Chem., 2014, 406, 2123-2131.

6 B. P. Patel and A. Kumar, Desalin. Water Treat., 2016, 57, 15932-15940.

7 R. Cheng, W. Zhou, J. L. Wang, D. D. Qi, L. Guo, W. X. Zhang and Y. Qian, J. Hazard. Mater., 2010, 180, 79-85.

8 J. N. Solanki and Z. Murthy, Ind. Eng. Chem. Res., 2011, 50, 14211-14216.

9 C. Sun, S. A. Baig, Z. Lou, J. Zhu, Z. Wang, X. Li, J. Wu, Y. Zhang and X. Xu, Appl. Catal., B, 2014, 158, 38-47.

10 A. A. Isse, B. Huang, C. Durante and A. Gennaro, Appl. Catal., $B, 2012,126,347-354$.

11 Y. H. Xu, Q. Q. Cai, H. X. Ma, Y. He, H. Zhang and C. A. Ma, Electrochim. Acta, 2013, 96, 90-96.

12 Z. Q. He, J. J. Sun, J. Wei, Q. Wang, C. X. Huang, J. M. Chen and S. Song, J. Hazard. Mater., 2013, 250, 181-189.

13 J. J. Li, H. L. Liu, X. W. Cheng, Q. H. Chen, Y. J. Xin, Z. P. Ma, W. X. Xu, J. Ma and N. Q. Ren, Chem. Eng. J., 2013, 225, 489498.

14 W. Y. Yu, G. M. Mullen and C. B. Mullins, J. Phys. Chem. C, 2013, 117, 19535-19543.

15 M. de Oca, H. Kurnarakuru, D. Cherns and D. J. Fermin, J. Phys. Chem. C, 2011, 115, 10489-10496.

16 S. R. de Debiaggi, E. A. Crespo, F. U. Braschi, E. M. Bringa, M. L. Ali and M. Ruda, Int. J. Hydrogen Energy, 2014, 39, 8590-8595. 
17 R. El Far, D. E. Diaz-Droguett, S. Rojas, J. I. Avila, C. P. Romero, P. Lievens and A. L. Cabrera, Thin Solid Films, 2012, 522, 199-203.

18 H. Ahmad, M. M. Rahman, M. A. Ali, H. Minami, K. Tauer, M. A. Gafur and M. M. Rahman, J. Magn. Magn. Mater., 2016, 412, 15-22.

19 Y. S. Ko and J. Yim, Polymer, 2016, 93, 167-173.

20 Z. R. Sun, X. F. Wei, Y. B. Han, S. Tong and X. Hu, J. Hazard. Mater., 2013, 244, 287-294.

21 Z. R. Sun, X. F. Wei, H. T. Shen and X. Hu, Electrochim. Acta, 2014, 129, 433-440.

22 Z. R. Sun, X. F. Wei, X. Hu, K. Wang and H. T. Shen, Colloids Surf., A, 2012, 414, 314-319.

23 Z. R. Sun, X. F. Wei, H. Zhang and X. Hu, Environ. Sci. Pollut. Res., 2015, 22, 3828-3837.

24 K. Yang and B. S. Xing, Chem. Rev., 2010, 110, 5989-6008.

25 M. Badard, A. Combessis, A. Allais and L. Flandin, Polymer, 2016, 82, 198-205.

26 K. Chu and S. Park, J. Ind. Eng. Chem., 2016, 35, 195-198.

27 J. Xu, X. S. Lv, J. D. Li, Y. Y. Li, L. Shen, H. Y. Zhou and X. H. Xu, J. Hazard. Mater., 2012, 225, 36-45.

28 Z. Sun, H. Zhang, X. Wei, R. Du and X. Hu, J. Electrochem. Soc., 2015, 162, H590-H596.

29 Z. Sun, H. Zhang, X. Wei, X. Ma and X. Hu, J. Solid State Electrochem., 2015, 19, 2445-2456.

30 Z. Sun, X. Wei, H. Shen and X. Hu, Electrochim. Acta, 2014, 129, 433-440.

31 Z. Sun, X. Wei, H. Zhang and X. Hu, Environ. Sci. Pollut. Res., 2015, 22, 3828-3837.

32 Z. Sun, X. Wei, H. Shen and X. Hu, Electrochim. Acta, 2014, 129, 433-440.

33 A. Fraczek-Szczypta, E. Dlugon, A. Weselucha-Birczynska, M. Nocun and M. Blazewicz, J. Mol. Struct., 2013, 1040, 238-245.

34 W. Qian, M. Cao, F. Xie and C. Dong, Nano-Micro Lett., 2016, 8, 240-246.
35 A. Benko, A. Przekora, A. Weselucha-Birczynska, M. Nocun, G. Ginalska and M. Blazewicz, Appl. Phys. A: Mater. Sci. Process., 2016, 122, 447.

36 K. A. Wepasnick, B. A. Smith, K. E. Schrote, H. K. Wilson, S. R. Diegelmann and D. H. Fairbrother, Carbon, 2011, 49, 24-36.

37 M. Hakamada, A. Moriguchi, S. Matsumura and M. Mabuchi, Thin Solid Films, 2013, 531, 99-102.

38 B. Thomas, A. R. Boccaccini and M. Shaffer, J. Am. Ceram. Soc., 2005, 88, 980-982.

39 A. Sarkar and D. Hah, J. Electron. Mater., 2012, 41, 31303138.

40 B. Yang, G. Yu and J. Huang, Environ. Sci. Technol., 2007, 41, 7503-7508.

41 Z. Sun, H. Shen, X. Wei and X. Hu, Chem. Eng. J., 2014, 241, 433-442.

42 G. Zhu, L. K. Pan, T. Lu, X. J. Liu, T. Lv, T. Xu and Z. Sun, Electrochim. Acta, 2011, 56, 10288-10291.

43 H. Cheng, K. Scott and P. A. Christensen, Electrochim. Acta, 2004, 49, 729-735.

44 J. T. Zhang, M. H. Huang, H. Y. Ma, F. Tian, W. Pan and S. H. Chen, Electrochem. Commun., 2007, 9, 1298-1304.

45 A. N. Correia, L. H. Mascaro, S. Machado and L. A. Avaca, Electrochim. Acta, 1997, 42, 493-495.

46 A. Pozio, M. De Francesco, A. Cemmi, F. Cardellini and L. Giorgi, J. Power Sources, 2002, 105, 13-19.

47 S. W. Li, Z. P. Dong, H. L. Yang, S. J. Guo, G. L. Gou, R. Ren, Z. J. Zhu, J. Jin and J. T. Ma, Chem.-Eur. J., 2013, 19, 23842391.

48 Z. R. Sun, K. Wang, X. F. Wei, S. Tong and X. Hu, Int. J. Hydrogen Energy, 2012, 37, 17862-17869.

49 Z. R. Sun, X. F. Wei, H. T. Shen and X. Hu, Electrochim. Acta, 2014, 129, 433-440.

50 A. I. Tsyganok, I. Yamanaka and K. Otsuka, Chemosphere, 1999, 39, 1819-1831.

51 J. Han, R. L. Deming and F. M. Tao, J. Phys. Chem. A, 2004, 108, 7736-7743. 